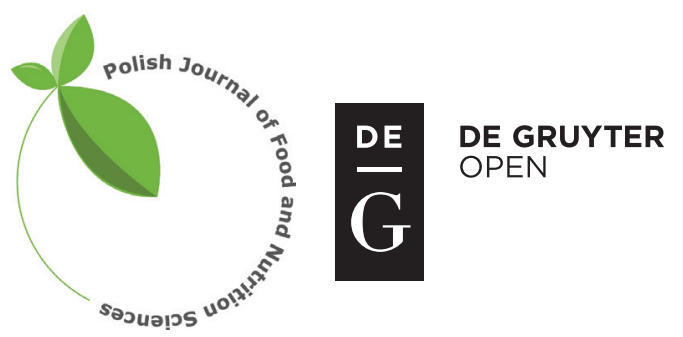

Pol. J. Food Nutr. Sci., 2016, Vol. 66, No. 4, pp. 261-269

DOI: $10.1515 /$ pjfns-2015-0057 http://journal.pan.olsztyn.pl

Original article

Section: Food Chemistry

\title{
Evaluation of the Organic Acids Ability for Extraction of Anthocyanins and Phenolic Compounds from Different Sources and Their Degradation Kinetics During Cold Storage
}

\author{
Sepideh Hosseini*, Maryam Gharachorloo, Babak Ghiassi-Tarzi, Mehrdad Ghavami \\ College of Food Science and Technology, Tehran Science and Research Branch, \\ Islamic Azad University, 1477893855 Tehran, Iran
}

Key words: anthocyanin, degradation kinetic, organic acids, phenolic compound, extraction, cold storage

The study of anthocyanin and phenolic acids has always received much attention due to their extensive range of colors and potential beneficial health effects. In this study extraction of anthocyanins from barberry, eggplant peel and red cabbage was investigated by using different organic solvents. Soluble solid content, antioxidant capacity, total monomeric anthocyanins and total phenolic content were determined and then degradation kinetics of anthocyanin in different solution during freezing process was assayed. In order to examine the effect of different acids on the degree of extraction of anthocyanin and total phenol, varied concentration of hydrochloric, citric and acetic acids were dissolved in a mixture of water and ethanol to prepare acidified aqueous solution. Results indicated that citric acid solution is one of the best solvents for phenolic and anthocyanin extraction which showed the best scavenging activity of DPPH radical. Results from degradation kinetics of total monomeric anthocyanins revealed that stability of anthocyanins in the solution depended on temperature and other ingredients which are present in the medium. Moreover, the present data confirmed that barberry and red cabbage acidified extracts could be one of the more stable natural food colorants based on anthocyanins.

\section{INTRODUCTION}

The study of natural colorants has always received much attention due to their potential beneficial health effects. Anthocyanins are most abundant vegetable pigments being used as natural food colorants [Giampieri et al., 2014a]. These pigments are harmless, easy soluble in the aqueous phase and might provide different colors (shiny orange, pink, red, violet and blue) in aqueous media, which makes them interesting for food products and beverages but huge variety of anthocyanin and their poor stability limits their application in the food industry [Forbes-Hernández et al., 2014].

Several factors such as $\mathrm{pH}$, storage temperature, chemical structure, concentration, light, oxygen, solvents, and the presence of enzymes, flavonoids, proteins and metallic ions influence the stability of extracted anthocyanins [Rein, 2005]. Since thermal treatments are unavoidable in food industries, many studies have been devoted to the effect of temperature, light, $\mathrm{pH}$, and thermal degradation of anthocyanins [Kamiloglu et al., 2013; Howard et al., 2014; Shao-Qian et al., 2011]. Among the fruits and vegetables that are good sources of anthocyanins, red cabbage has attracted much attention because of its physiological functions and applications. It has a significant amount of anthocyanins with high health-related properties [McDougall et al., 2007]. Cyanidin glycosides in most

\footnotetext{
* Corresponding Author: Tel.: +982144868541; Fax: +982144868541;

E-mail: sepidehpaeizan@yahoo.com (Sepideh Hosseini)
}

cases, are the main anthocyanin pattern that are followed by pelargonidin glucoside and peonidin glucosides [Charron et al., 2009; McDougall et al., 2007]. Red cabbage dye is valued in food systems as a natural colorant or in pharmaceutical formulations as a pH indicator [Silva-Pereira et al., 2015]. However, there is lack of studies comparing stability of red cabbage extract in different organic solvents.

Recently eggplant (Solanum melongena) peel has attracted much attention as an important source of phenolic and flavonoid compounds. Nasunin (delphinidin-3-p-coumaroylrutinoside-5-glucoside) is its major anthocyanin [Gallo et al., 2014] which has the strongest antioxidant activity in vitro among other anthocyanins [Igarashi et al., 1993]. Some studies were carried out on improving anthocyanin extraction from eggplant peel [Boulekbache-Makhlouf et al., 2013; Todaro et al., 2009]. Their results showed that methanol and tartaric acid 70:30(V/V) were more efficient solvents for anthocyanins extraction.

Barberry (Berberis L.) is one of the traditional Iranian pharmacopoeia which is also consumed as a food additive [Berenji Ardestani et al., 2013]. Barberry has been shown to possess some activity against fungal infections, Candida albicans, yeast, parasites, and bacterial infections which are attributable to active ingredients including isoquinolone alkaloids, especially berberine [Sharifi \& Hassani, 2012; Koncic et al., 2010]. Berberis vulgaris contains pelargonidin-3-glucoside and cyanidin-3-glucoside as predominating anthocyanins $(931.05 \pm 21.31 \mathrm{mg} / \mathrm{kg}$ fresh fruit), high concentrations of vitamin $\mathrm{C}$ and other bioactive substances such as iron, 
zinc, and calcium [Akbulut et al., 2009; Berenji Ardestani et al., 2013].

In this study, extraction of anthocyanins from barberry, eggplant peel and red cabbage was investigated by using different organic solvents. Soluble solid content, antioxidant capacity, total monomeric anthocyanins and total phenolic content were determined as well. The stability of anthocyanins during storage at ambient and cold temperatures was considered less attractive by scientific research therefore, the degradation kinetics of anthocyanins during freezing processes was evaluated as the second aim of this study.

\section{MATERIAL AND METHODS}

Fresh barberry (Berberis vulgaris), eggplant (Solanum melongena) and red cabbage (Brassica oleracea) were purchased from a local market in Tehran, Iran. and used fresh daily. The initial moisture content of the samples in wet basis (\%) was $75.47,89.29$ and 93.46 for barberry, eggplant peel and red cabbage respectively. DPPH (2, 2-Diphenyl-1-picrylhydrazyl) and Folin-Ciocalteu were purchased from Sigma (Sigma-Aldrich Co. USA). All solvents and other chemicals were obtained from Merck (Merck KGaA, Germany).

\section{Extraction}

In brief, $15 \mathrm{~g}$ of each sample (red cabbage, barberry and peel of eggplant which was manually removed) were chopped, mixed in a commercial blender (Philips, HR777803) with $100 \mathrm{~mL}$ of different solvents (water, absolute ethanol, water/ethanol 50:50 (v/v), water/ ethanol/ citric acid, water/ ethanol/ acetic and water/ ethanol/ hydrochloric acid) 50:48:2 (v/v/v) separately for 60 mins in the dark. According to the experiences of previous study, the $\mathrm{pH}$ changes could affect the extraction yield [Chandrasekhar et al., 2012]. Therefore, the volumes of acids were supposed to be constant and their different concentrations were applied to maintain a constant $\mathrm{pH}$ of the medium. The extract was filtered through a $0.45 \mathrm{~mm}$ cellulose filter paper (Schleicher \& Schuell, Dassel, Germany) and used for analysis. In order to know the efficiency of the extraction medium, the number of extractions was restricted to only one. In other words, after the first extraction the filter cake obtained was discarded although it contained some amount of anthocyanins. The individual filtrates obtained from different extraction media were centrifuged separately at $6000 \mathrm{rpm}$ for about $15 \mathrm{~min}$ to remove the fine suspended particles and applied for the following analysis.

\section{Determination of anthocyanin contents}

The total monomeric anthocyanin content was determined by the $\mathrm{pH}$ differential method [Giusti \& Wrolstad, 2003]. Two dilutions of the same sample were prepared using $0.025 \mathrm{~mol} / \mathrm{L}$ potassium chloride solution and $0.4 \mathrm{~mol} / \mathrm{L}$ sodium acetate solution adjusted to $\mathrm{pH} 1.0$ and 4.5 with hydrochloric acid, respectively. The absorbance of each dilution was measured at 512 and $700 \mathrm{~nm}$ against a distilled water blank using a UV-visible spectrometer (Varian CARY 100 Bio). Anthocyanin content was calculated from the Equation (1) [Sigh et al., 2006].

$$
\text { Anthocyanin pigment }=\frac{\mathrm{A} \times \mathrm{Mw} \times \mathrm{DF} \times 10^{3}}{\varepsilon \times \mathrm{I}}
$$

where: Mw is the molecular weight of anthocyanin $(449.2 \mathrm{~g} / \mathrm{mol})$, DF is the dilution factor, $\varepsilon$ is the extinction coefficient $(26,900 \mathrm{~L} /$ $\mathrm{cm} \mathrm{mol})$ and I is the path length $(1 \mathrm{~cm})$ and expressed in cyanidin-3-glucoside equivalents, $\mathrm{mg} / \mathrm{L}$.

\section{Total phenolic content}

The modified Folin-Ciocalteu procedures [Giampieri et al., 2014b] were utilized in this study. Gallic acid stock solution $(1 \mathrm{mg} / \mathrm{mL})$ and working standard concentrations of $0,10,25,50,100,250$ and $500 \mathrm{mg} / \mathrm{mL}$ (parts per million, $\mathrm{ppm})$ were prepared in deionized water $\left(\mathrm{DIH}_{2} \mathrm{O}\right)$. The modified Folin-Ciocalteu procedure consisted in transferring $50 \mu \mathrm{L}$ of the standard or a sample into a $4-5 \mathrm{~mL}$ borosilicate tube, followed by additions of $430 \mu \mathrm{L}$ of $\mathrm{DIH}_{2} \mathrm{O}$ and $20 \mu \mathrm{L}$ of Folin-Ciocalteu reagent. After mixing the samples, $50 \mu \mathrm{L}$ of $20 \% \mathrm{Na}_{2} \mathrm{CO}_{3}$ and $450 \mu \mathrm{L}$ of $\mathrm{DIH}_{2} \mathrm{O}$ were added. The sample mixtures were allowed to stand for $1 \mathrm{~h}$ at room temperature and were mixed after addition of each reagent. Aliquots of $200 \mu \mathrm{L}$ were transferred to clear microtitre wells in duplicate and the absorbance was determined at $725 \mathrm{~nm}$ using a Biotek Synergy HT. The phenolic content of the samples was reported against the gallic acid (GA) calibration standard (0-500 ppm) [Medina, 2011].

\section{DPPH assay}

$\mathrm{DPPH}^{\cdot}$ has an intense violet color with a maximum absorbance at $517 \mathrm{~nm}$, but turns colorless as unpaired electrons are scavenged by antioxidants. Reaction mixtures containing $0.1 \mathrm{~mL}$ of the sample and $3.9 \mathrm{~mL}$ of $200 \mu \mathrm{mol} / \mathrm{L} \mathrm{DPPH}^{*}$ (prepared in ethanol) were incubated in a water bath at $37^{\circ} \mathrm{C}$ for $30 \mathrm{~min}$. After incubation, the absorbance was measured at $517 \mathrm{~nm}$. The percentage inhibition was calculated against a control [Konczak \& Zhang, 2004].

\section{Degradation kinetics}

In order to evaluate the stability of anthocyanins during the cold storage and investigate the effect of citrate on their degradation kinetics, anthocyanins were extracted from red cabbage, barberry and eggplant peel by water/ethanol/citric acid (50:48:2) and their solvent was evaporated by rotary instruments (Heidolph, Germany). Solid matters were dissolved in water, citrate and glycine hydrochloric acid buffer solutions where the initial concentration of anthocyanin was $30 \mathrm{mg} /$ $\mathrm{mL}$ in all solutions. All buffers were prepared in $100-\mathrm{mL}$ volumetric flasks with purified deionized water and the final $\mathrm{pH}$ was adjusted to 3.7. The citrate buffer was prepared by adding $37 \mathrm{~mL}$ of $0.1 \mathrm{~mol} / \mathrm{L}$ citric acid solution and $13 \mathrm{~mL}$ of $0.1 \mathrm{~mol} / \mathrm{L}$ sodium citrate solution, then water was added to bring the solution up to the final volume. The glycine hydrochloric acid buffer was prepared by adding $25 \mathrm{~mL}$ of $0.2 \mathrm{~mol} / \mathrm{L}$ glycine solution, $2.5 \mathrm{~mL}$ of $1 \mathrm{~mol} / \mathrm{L}$ hydrochloric acid solution and then adding water to the final volume. The solutions were freshly prepared and $\mathrm{pH}$ values were measured at room temperature of $25^{\circ} \mathrm{C}$ by a portable $\mathrm{pH}$ meter (Omega, $\mathrm{PHH}$ 222). It is worth mentioning that glycine hydrochloric acid buffer has been applied only to eliminate the effects of $\mathrm{pH}$ 
on anthocyanins stability results. The thermal stability of anthocyanins was studied at 7 and $-20^{\circ} \mathrm{C}$ for 30 days. Aliquots of $20 \mathrm{~mL}$ portions of different solutions were put into plastic tubes, then the sample tubes covered with aluminum foil were well capped to avoid evaporation and placed in an incubator, conventional refrigerator and freezer to a given temperature. Tubes were randomly taken from the storage at regular time intervals and defrosted at ambient temperature. The contents of tubes were analyzed for monomeric anthocyanin content.

\section{Statistical analysis}

All extraction processes were conducted with two replications and each treatment extract was analyzed so the results were presented as mean \pm SD based on them. Analysis of variance was performed by ANOVA procedure with one factor. Differences were considered significant at $\mathrm{p}<0.05$.

\section{RESULTS AND DISCUSSION}

\section{Physical and chemical characteristics of extracts}

In order to examine the effect of different kinds of the acids on the degree of extraction of anthocyanins and total phenols, hydrochloric, citric and acetic acids were dissolved in a mixture of water and ethanol to prepare acidified aqueous extractor with constant $\mathrm{pH}$. Soluble solids and $\mathrm{pH}$ of mediums are shown in Table 1. In red cabbage and eggplant peel, extraction with hydrochloric acid showed the highest $\mathrm{pH}$ between acidified solutions that might be incurred by pectin or protein hydrolysis. Hydrochloric acid is a catalyst for the hydrolysis of most of organic compounds. It seems that in acidic conditions, the liberation of some pectin, sugars, essentially galactose, glucose, and rhamnose happened but not completely. Acidic hydrolysis rates for polypectate $(<5 \% \mathrm{DM})$ declined as the $\mathrm{pH}$ value was raised from 2 to 6 . Pectin $(35 \%$ and $70 \%$ $\mathrm{dm}$ ) hydrolyzed more slowly than polypectate below $\mathrm{pH} 3.5$, but then degradation rates increased because $\beta$-elimination became the dominant reaction above $\mathrm{pH} 3.8$ [Garna et al., 2004]. The results indicate that carboxylic acids could not catalyze the degradation of cell wall polysaccharides as well as mineral acid since acid-catalyzed hydrolysis is proportional to $\mathrm{H}+$ concentration [Mosier et al., 2002].

As expected, we failed to show any significant difference in the barberry extracts which would be due to lack of the com- plex polysaccharide and protein in barberry cell wall that could be extensively hydrolyzed by acid and increased $\mathrm{pH}$.

Brix degrees or total soluble solids are mostly used in the fruit industry to evaluate the concentration of liquids. Brix degrees in various solutions are significantly different $(p<0.05)$ and ethanol has a great potential effect on soluble solids extraction (Table 1), but results in the Tables 2, 3 and 4 indicate that Brix is not an appropriate scale for predicting phenolic compounds concentration.

\section{Phenolic and anthocyanin contents}

Acidified aqueous mixtures of ethanol, methanol or acetone are commonly used for the extraction of phenolics and anthocyanins from fruits and vegetables [Astadi et al., 2009; Chandrasekhar et al., 2012]. Methanolic extraction is more effective than ethanolic but in food technology methanol is not preferred due to its toxicity [Kapasakalidis et al., 2006]. Results of previous studies showed that hydrochloric acid has a potential ability to accelerate extraction of total phenols and anthocyanins [Castaneda-Ovando et al., 2009; Li et al., 2013].

There are also reports that the organic acids like acetic or formic acids might destroy the cell membranes, simultaneously dissolve the phenolics and anthocyanins and stabilize them [Todaro et al., 2009; Mosier et al., 2002]. The effects of solvents on anthocyanins extracted from red cabbage (Brassica oleracea), eggplant peel (Solanum melongena) and barberries (Berberis vulgaris) are discussed in the following sections. Since the $\mathrm{pH}$ of acidified solvent highly influences the final content of anthocyanins, the extraction is conducted at constant initial $\mathrm{pH}(\mathrm{pH}=3.49)$.

\section{Red cabbage (Brassica oleracea)}

The content of phenolic compounds in the red cabbage extract ranged from 529.60 to $724.14 \mathrm{mg} / 100 \mathrm{~g}$ of FW in ethanol and citric acid solvents, respectively. It is known that phenolic compounds are polar molecules, thus extraction is highly influenced by polarity. Among the non-acidified solvents, water was more efficient than ethanol due to higher polarity (dipole momentum of water and ethanol are 1.95 and $1.69 \mathrm{D}$, respectively). As presented in Table 2, citric acid ensured the highest content of the total phenolics among the six media. It might be attributed to high hydrolyzing and polarity activity and also

TABLE 1. pH of red cabbage, barberry and eggplant peel extracts.

\begin{tabular}{|c|c|c|c|c|c|c|c|}
\hline \multirow{2}{*}{ Extract } & \multirow{2}{*}{$\mathrm{pH}^{*}$} & \multicolumn{2}{|c|}{ Red cabbage } & \multicolumn{2}{|c|}{ Barberry } & \multicolumn{2}{|c|}{ Eggplant peel } \\
\hline & & $\mathrm{pH}^{* *}$ & Brix $(\%)$ & $\mathrm{pH}^{* *}$ & $\operatorname{Brix}(\%)$ & $\mathrm{pH}^{* *}$ & Brix $(\%)$ \\
\hline Distilled water (100) & 5.75 & 6.30 & 2.00 & 3.46 & 2.80 & 5.24 & 1.97 \\
\hline Ethanol (100) & 7.80 & 6.85 & 21.50 & 4.90 & 21.09 & 6.17 & 20.11 \\
\hline Water/ethanol (50:50) & 6.90 & 6.64 & 14.22 & 3.99 & 17.25 & 4.98 & 14.93 \\
\hline Water/ethanol/citric acid (50:48:2) & 3.49 & 4.59 & 14.83 & 3.79 & 17.71 & 4.15 & 14.32 \\
\hline Water/ethanol/acetic acid (50:48:2) & 3.49 & 4.38 & 15.12 & 3.78 & 17.76 & 4.14 & 15.10 \\
\hline Water/ethanol/hydrochloric acid (50:48:2) & 3.49 & 5.60 & 15.17 & 3.78 & 16.47 & 5.33 & 15.56 \\
\hline
\end{tabular}

*Initial $\mathrm{pH}$ of solvent; ** pH of extractions. 
TABLE 2. Concentration of total phenols, anthocyanins and DPPH scavenging capacity in red cabbage extracts.

\begin{tabular}{|c|c|c|c|}
\hline Extract & $\begin{array}{c}\text { Total phenols } \\
\text { (mg GAE / } 100 \mathrm{~g}) \mathrm{FW}\end{array}$ & $\begin{array}{l}\text { Anthocyanins } \\
\text { (mg/100 g) FW }\end{array}$ & $\begin{array}{c}\text { DPPH } \\
\text { (\%) inhibition } \\
\end{array}$ \\
\hline Water (100) & $657.06 \pm 12.78^{b}$ & $53.23 \pm 2.68^{\mathrm{e}}$ & $71.56 \pm 0.82^{c}$ \\
\hline Ethanol (100) & $529.60 \pm 8.19^{d}$ & $78.09 \pm 1.58^{c}$ & $56.82 \pm 1.81^{\mathrm{f}}$ \\
\hline Water/ ethanol (50:50) & $549.12 \pm 18.67^{d}$ & $61.78 \pm 2.83^{\mathrm{d}}$ & $76.40 \pm 1.39^{\mathrm{d}}$ \\
\hline Water/ ethanol/citric acid (50:48:2) & $724.14 \pm 11.99^{a}$ & $115.43 \pm 5.94^{\mathrm{a}}$ & $89.81 \pm 1.63^{\mathrm{a}}$ \\
\hline Water/ ethanol/acetic acid (50:48:2) & $593.95 \pm 14.17^{\mathrm{c}}$ & $71.64 \pm 3.59^{c}$ & $81.45 \pm 1.08^{b}$ \\
\hline Water/ ethanol/hydrochloric acid (50:48:2) & $587.20 \pm 10.93^{\mathrm{c}}$ & $90.37 \pm 2.53^{b}$ & $64.13 \pm 2.66^{\mathrm{e}}$ \\
\hline
\end{tabular}

Notes: Values are averages \pm standard deviation of duplicate analysis; different letters in same column indicate significant difference $(\mathrm{P}<0.05$; Duncan's multiple test). FW: Fresh Weight. GAE: Gallic Acid Equivalent.

some individual characteristics of chelation ability of metal ions. One of the main characteristics of anthocyanins and anthocyanidins with o-di-hydroxyl groups in the B ring, is their ability to form metal-anthocyanin complexes [Boulton, 2001] which could be carried out in fruits and vegetables like red cabbage. Whereas citric acid has a strong chelating ability to anthocyanins; co-pigment can dissolve the anthocyanins, and stabilize them. Therefore, higher phenol and anthocyanin contents were obtained. The contents of phenolic compounds in the extracts obtained by acetic and hydrochloric acids did not differ significantly $(p<0.05)$. Despite the fact that acetic acid $(1.74 \mathrm{D})$ has a higher dipole momentum than hydrochloric acid (1.08 D), but hydrochloric acid has a higher hydrolyzing ability of cell membrane would lead to closely similar results.

The content of anthocyanins in red cabbage is given in Table 2 . High variability $(\mathrm{p}<0.05)$ in anthocyanin concentrations was observed among red cabbage extracts. The contents of extracted anthocyanins are as follow: citric acid 115.43, hydrochloric acid 90.37, ethanol 78.09, acetic acid 71.64, water/ethanol 61.78, and water $53.23 \mathrm{mg} / 100 \mathrm{~g} \mathrm{FW}$. Based on these results the acidified solutions exhibit higher amounts of anthocyanins. In acidic conditions, the flavylium cation (red color) is a predominant species. Increasing $\mathrm{pH}$ hydrated this ion slowly to purple quinonoidal bases that these compounds are labile. In the presence of strong acids like hydrochloric and sulfuric acid, hydrolysis reactions are carried out and a glycosyl group in the location of glycosidic residues is replaced by a hydrogen atom and aglycone is produced [Fleschhut et al., 2006]. Thus extraction is facilitated by weak acid [Holzwarth et al., 2012].

The greatest anthocyanin contents were obtained by citric acid. As mentioned earlier, it would be associated with its chelating ability. At $\mathrm{pH}$ conditions typically used for extraction (pH 4-6), four structural forms of the anthocyanins coexist: flavylium cation, anhydrous quinoidal base, colorless carbinol base and the pale yellow chalcone [Chen et al., 2013]. The counter-ion of the flavylium cation would be co-pigments to organic acid which could lead to increased extraction efficiency and higher stability.

However, there are many studies which demonstrated that anthocyanins are polar pigments but they usually may not exhibit high hydrophilicity. As an example, cyanidin 3-glucoside which is the predominant anthocyanin of red cabbage [McDougall et al., 2007] indicates $\log$ p 0.386-0.5 (log p means the log- arithm of the molecular 1-octanol-water partition coefficient of compounds). Positive log p of cyanidin 3-glucoside indicates that this material also tends to non-polar solvents. In this respect, citric acid is significantly better extractor than others.

\section{Barberry (Berberis vulgaris)}

As it can be seen in Table 3, the aquatic extract of barberry exhibited good total phenolic and anthocyanin contents, as a consequence had higher DPPH scavenging ability which followed by citric acid, water/ethanol, acetic acid and hydrochloric acid $(p<0.05)$, that might be explained by the structure of specific type of cell wall of barberry which does not require hydrolysis to release phenolic compounds. In the absence of the results which were obtained by citric acid, the polarity of the solvents probably is the most important factor defining the extraction of phenolic and anthocyanins compounds.

\section{Eggplant (Solanum melongena) peel}

Table 4 shows the total phenolic contents of eggplant peel extracts, which are significantly different $(p<0.05)$. Todaro et al. [2009] found that the phenolic content of acidified ethanolic extract of fresh eggplant peels was $188.73 \pm 73 \mu \mathrm{g}$ GAE/mL of extract. In turn, Nisha and his collaborators [2009] have reported $49.02 \pm 1.3 \mathrm{mg} \mathrm{GAE} / 100 \mathrm{~g}$ DE in the methanolic extract and Eun-Ju et al. [2011] have found 55.19 $\pm 1.3 \mathrm{mg}$ GAE/100 g DE in 70\% ethanolic extract of fresh eggplant peel. These differences in phenolic contents might be due to the extraction condition (time and temperature).

The total anthocyanin contents of eggplant peel varied in the different extracts (Table 4). The highest level has been detected in citric acid extract (51.40 mg /100 g FW), followed by acetic acid, hydrochloric acid, ethanol and water extracts (43.27, 37.29, 16.66, 9.38 and 5.61 mg /100 g FW, respectively).

\section{DPPH radical scavenging capacity}

The measured inhibition of DPPH radical, for all red cabbage extracts are shown in Table 2. Citric acid shows the highest antioxidant activity followed by acetic acid, water, hydrochloric acid and ethanol. These variations are mostly attributed to anthocyanin contents. Some extracts demonstrated the lowest antioxidant activity even with high total phenolic contents. There was a significant variation in the DPPH radical-scavenging ability of barberry extracts (52.24-96.60\%) (Table 3). Correlations between the scavenging activity obtained from 
TABLE 3. Concentration of total phenols, anthocyanins and DPPH scavenging capacity in barberry extracts.

\begin{tabular}{lcc|c}
\hline Extract & $\begin{array}{c}\text { Total phenols } \\
(\mathrm{mg} \mathrm{GAE} / 100 \mathrm{~g}) \mathrm{FW}\end{array}$ & $\begin{array}{c}\text { Anthocyanins } \\
(\mathrm{mg} / 100 \mathrm{~g}) \mathrm{FW}\end{array}$ & $\begin{array}{c}\text { DPPH } \\
(\%) \text { inhibition }\end{array}$ \\
\hline Water (100) & $2636.16 \pm 11.86^{\mathrm{a}}$ & $47.69 \pm 1.39^{\mathrm{a}}$ & $96.60 \pm 1.03^{\mathrm{a}}$ \\
Ethanol (100) & $2250.04 \pm 29.89^{\mathrm{f}}$ & $35.12 \pm 2.24^{\mathrm{b}}$ & $82.46 \pm 2.89^{\mathrm{e}}$ \\
Water/ ethanol (50:50) & $2502.27 \pm 7.81^{\mathrm{c}}$ & $25.48 \pm 1.49^{\mathrm{c}}$ & $90.00 \pm 1.91^{\mathrm{b}}$ \\
Water/ ethanol/citric acid (50:48:2) & $2595.42 \pm 7.84^{\mathrm{b}}$ & $33.76 \pm 3.00^{\mathrm{b}}$ & $77.78 \pm 2.17^{\mathrm{a}}$ \\
Water/ ethanol/acetic acid (50:48:2) & $2424.25 \pm 9.52^{\mathrm{d}}$ & $20.12 \pm 0.26^{\mathrm{d}}$ & $64.92 \pm 1.71^{\mathrm{c}}$ \\
Water/ ethanol/hydrochloric acid (50:48:2) & $2391.27 \pm 13.58^{\mathrm{e}}$ & $15.36 \pm 1.47^{\mathrm{e}}$ & $52.24 \pm 2.99^{\mathrm{d}}$ \\
\hline
\end{tabular}

Notes: Values are averages \pm standard deviation of duplicate analysis; different letters in same column indicate significant difference ( $\mathrm{P}<0.05$; Duncan's multiple test). FW: Fresh Weight. GAE: Gallic Acid Equivalent.

TABLE 4. Concentration of total phenols, anthocyanins and DPPH scavenging capacity in eggplant peel extracts.

\begin{tabular}{lcc|c}
\hline Extract & $\begin{array}{c}\text { Total phenols } \\
(\mathrm{mg} \mathrm{GAE} / 100 \mathrm{~g}) \mathrm{FW}\end{array}$ & $\begin{array}{c}\text { Anthocyanins } \\
(\mathrm{mg} / 100 \mathrm{~g}) \mathrm{FW}\end{array}$ & $\begin{array}{c}\text { DPPH } \\
(\%) \text { inhibition }\end{array}$ \\
\hline Water (100) & $66.06 \pm 2.71^{\mathrm{f}}$ & $9.38 \pm 1.38^{\mathrm{f}}$ & $24.09 \pm 2.80^{\mathrm{f}}$ \\
Ethanol (100) & $184.26 \pm 4.86^{\mathrm{d}}$ & $16.66 \pm 1.44^{\mathrm{d}}$ & $47.65 \pm 0.94^{\mathrm{d}}$ \\
Water/ ethanol (50:50) & $125.17 \pm 2.44^{\mathrm{e}}$ & $5.61 \pm 1.06^{\mathrm{e}}$ & $37.31 \pm 1.88^{\mathrm{e}}$ \\
Water/ ethanol/citric acid (50:48:2) & $217.32 \pm 2.12^{\mathrm{b}}$ & $51.40 \pm 2.43^{\mathrm{a}}$ & $71.68 \pm 2.01^{\mathrm{a}}$ \\
Water/ ethanol/acetic acid (50:48:2) & $207.79 \pm 4.20^{\mathrm{c}}$ & $43.27 \pm 1.24^{\mathrm{b}}$ & $56.72 \pm 0.097^{\mathrm{c}}$ \\
Water/ ethanol/hydrochloric acid (50:48:2) & $230.02 \pm 3.12^{\mathrm{a}}$ & $37.29 \pm 2.32^{\mathrm{c}}$ & $63.86 \pm 2.19^{\mathrm{b}}$
\end{tabular}

Notes: Values are averages \pm standard deviation of duplicate analysis; different letters in same column indicate significant difference $(\mathrm{P}<0.05$; Duncan's multiple test). FW: Fresh Weight. GAE: Gallic Acid Equivalent.

all barberry extracts are total phenols and anthocyanins are $0.95-0.43 \%$ respectively. It means that the free radical scavenging activity depends mostly on the total phenols content. In fact, the presence of bioactive compounds that have a high antioxidant activity such as berberine, vitamin $\mathrm{C}$ and phenolic acids, affect more DPPH ${ }^{\bullet}$ radical scavenging than anthocyanins do. Therefore, anthocyanins are not considered the most effective antioxidants in barberry extracts.

The DPPH scavenging capacity of eggplant peel varied significantly $(p<0.05)$ between $24.09 \%$ and $71.68 \%$ (Table 4 ). The free radical scavenging activity of eggplant peel extracts was highly dependent on anthocyanins contents with a correlation coefficient of 0.97 . It can be concluded that anthocyanins are the largest class of compounds with the antioxidant activity in the peel of eggplant.

\section{Degradation kinetics of total monomeric anthocyanins}

Maintenance of naturally colored pigments in processed and stored foods is the major challenge in food processing. Therefore, the stability of anthocyanins as food colorants in aqueous solutions was evaluated and the anthocyanin contents of solution during cold storage were plotted with a regular interval of 5 days. The degradation of monomeric anthocyanins of the solution followed the first order reaction kinetics with respect to temperature. This kinetic type is expressed by the Equation (2).

$$
\mathrm{C}=\mathrm{C}_{0} \times \exp \left( \pm \mathrm{k}_{1} \times \mathrm{t}\right)
$$

where $\mathrm{C}_{0}$ is the initial anthocyanin content and $\mathrm{C}$ is the anthocyanin content after time $\mathrm{t}$ ( $\mathrm{min}$ ) of heating at the given temperature while $\mathrm{k}_{1}\left(\mathrm{~min}^{-1}\right)$ is the first order rate constant. Half-life $\left(\mathrm{t}_{1 / 2}\right)$ which is the time needed for $50 \%$ degradation is calculated by the Equation (3).

$$
\mathrm{t}_{1 / 2}=-\ln 0.5 / k_{1}
$$

where $t_{1 / 2}$ is the half-life and $k_{1}$ is the first order degradation rate constant $\left(\mathrm{h}^{-1}\right)$.

The effect of temperature on the degradation rate constants is expressed by the linearized Arrhenius equation by plotting $\ln \mathrm{k}$ against $1 / \mathrm{T}$ in which the temperature dependence of $\mathrm{k}$ is quantified by the activation energy Ea according to Equation (4).

$$
\ln k=\ln A_{0}-E_{a} / R T
$$

where $\mathrm{k}$ is the rate constant $\left(\mathrm{min}^{-1}\right), \mathrm{A}_{0}$ is the frequency factor $\left(\mathrm{min}^{-1}\right), \mathrm{Ea}$ is the activation energy $(\mathrm{kJ} / \mathrm{mol}), \mathrm{R}$ is the universal gas constant $(8.314 \mathrm{~J} / \mathrm{mol} / \mathrm{K})$ and $\mathrm{T}$ is the absolute temperature (Kelvin, $\mathrm{K}$ ). The Ea value is calculated from the slope of the straight lines given by Equation (4) [Cao et al., 2011; Jing et al., 2012; Kara \& Ercelebi, 2013]. 

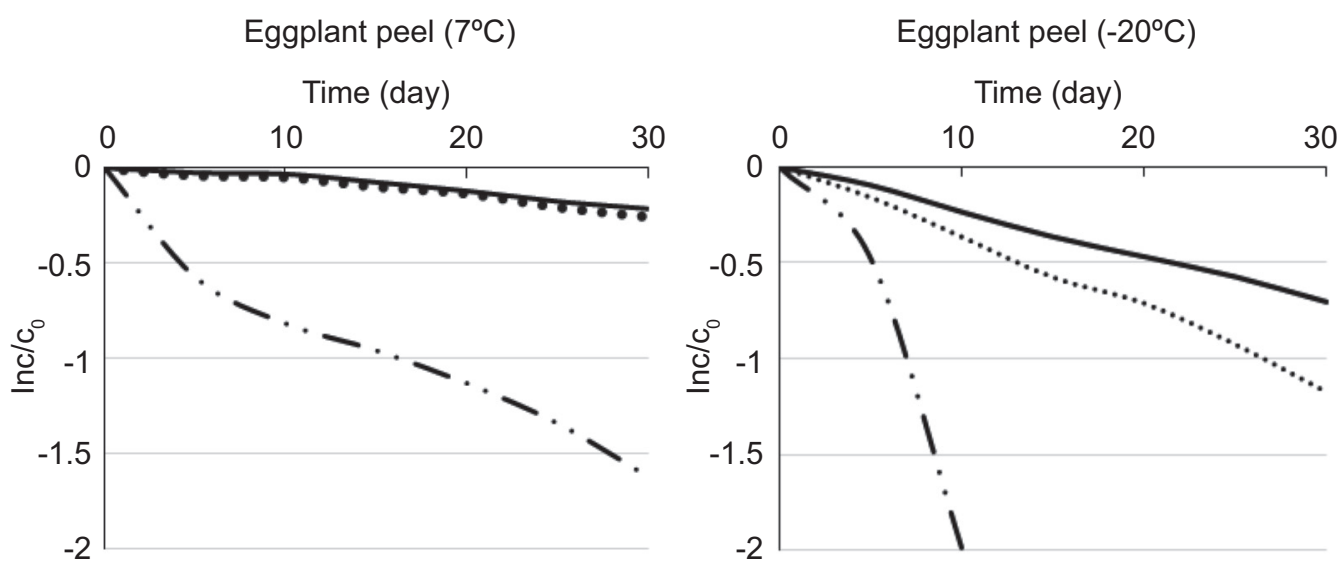

FIGURE. 1. Evolution of the concentration of monomeric anthocyanins of eggplant peel with time at the different temperatures $(-\cdot \cdot-$ Water, - glycine $\mathrm{HCl}$ buffer and $\cdots$... citrate buffer).
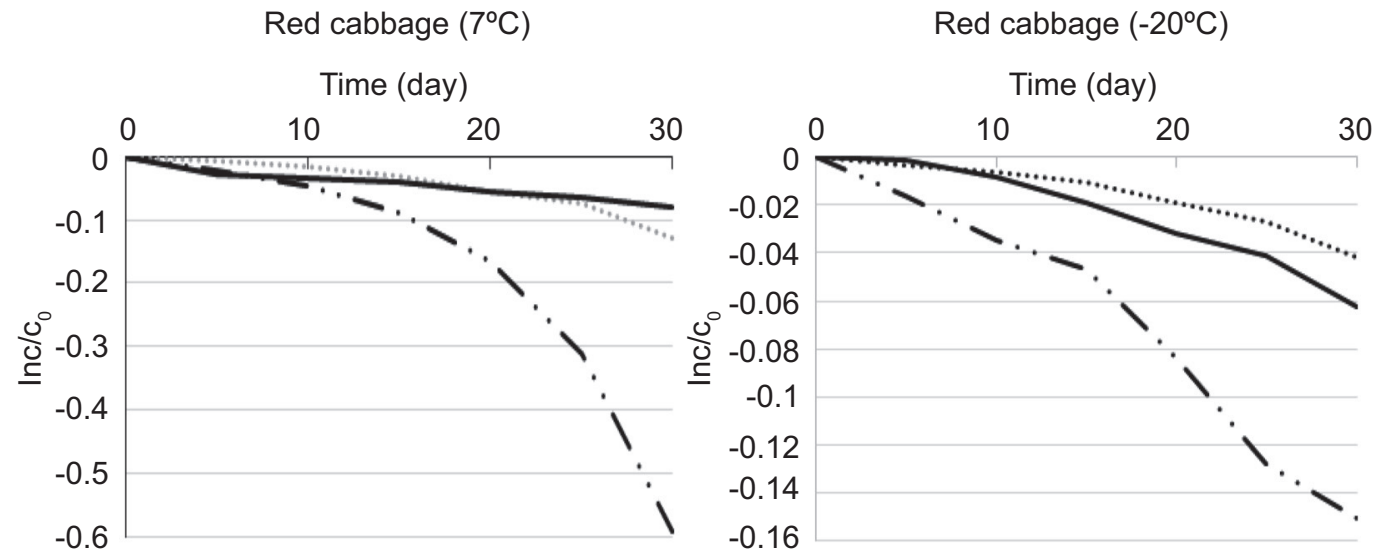

FIGURE. 2. Evolution of the concentration of monomeric anthocyanins of red cabbage with time at the different temperatures $(-\cdot \cdot-$ Water, - glycine $\mathrm{HCl}$ buffer and $\cdots .$. citrate buffer).
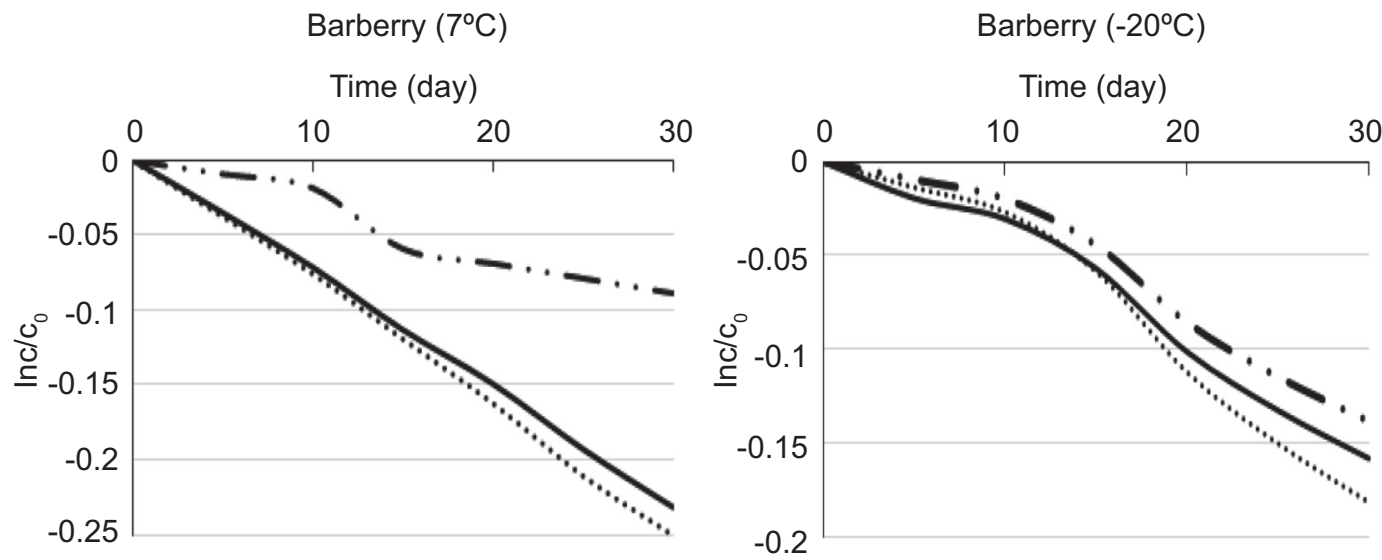

FIGURE. 3. Evolution of the concentration of monomeric anthocyanins of barberry with time at the different temperatures $(-\cdot \cdot-$ Water, - glycine $\mathrm{HCl}$ buffer and $\cdots .$. citrate buffer).

The logarithms of anthocyanin contents of eggplant peel, red cabbage and barberry during cold storage were plotted with a regular interval of 5 days (Figures 1-3).

In each figure, the acidified solutions show the same behavior. There was no difference between buffers during 30 days of storage at $7^{\circ} \mathrm{C}$ but solutions containing citrate showed greater stability after the day tenth at $-20^{\circ}$ C. The similar behavior of buffers might be due to the effects of $\mathrm{pH}$ on the stability of anthocyanins. This is in agreement with findings reported by Kirca et al. [2003]. They evaluated the effect of $\mathrm{pH}$ on thermal stability of anthocyanins from black carrots at six different pHs (2.5-7.0) in citrate-phosphate buffer solutions and observed a significant decrease in anthocyanin stability at $\mathrm{pHs}$ above 5.0. In a water-based solution $(\mathrm{pH}=5.24)$ of eggplant peel and red cabbage, the degradation of anthocyanins during cold storage en- 
TABLE 5. Thermal degradation parameters of anthocyanin during cold storage.

\begin{tabular}{|c|c|c|c|c|c|c|}
\hline \multirow{2}{*}{ Sample } & \multirow{2}{*}{ Medium } & \multicolumn{2}{|c|}{$\mathrm{k}(\mathrm{h})^{-1 \mathrm{a}}$} & \multicolumn{2}{|c|}{$\mathrm{t}_{1 / 2}(\text { day })^{\mathrm{b}}$} & \multirow{2}{*}{$\frac{\mathrm{E}_{\mathrm{a}}\left(\mathrm{kJ} \mathrm{mol}{ }^{-1}\right)^{\mathrm{c}}}{\mathrm{T}>0}$} \\
\hline & & 7 & -20 & 7 & -20 & \\
\hline \multirow{3}{*}{ Red cabbage } & Water & $0.0156(0.9775)^{\mathrm{d}}$ & $0.0102(0.9835)$ & 44.43 & 67.95 & 9.62 \\
\hline & Citrate buffer & $0.0043(0.9833)$ & $0.0026(0.9764)$ & 161.19 & 266.59 & 10.97 \\
\hline & Glycine $\mathrm{HCl}$ buffer & $0.0044(0.9835)$ & $0.0029(0.9915)$ & 157.53 & 239.01 & 9.09 \\
\hline \multirow{3}{*}{ Eggplant peel } & Water & $0.0479(0.9510)$ & $0.1619(0.9447)$ & 14.47 & 4.28 & 26.56 \\
\hline & Citrate buffer & $0.0085(0.9639)$ & $0.0387(0.9958)$ & 93.66 & 17.91 & 33.06 \\
\hline & Glycine $\mathrm{HCl}$ buffer & $0.0074((0.9629)$ & $0.0236(0.9981)$ & 81.54 & 29.37 & 25.29 \\
\hline \multirow{3}{*}{ Barberry } & Water & $0.0033(0.9485)$ & $0.0049(0.9762)$ & 210.04 & 141.45 & 8.60 \\
\hline & Citrate buffer & $0.0052(0.9355)$ & $0.0055(0.9834)$ & 133.29 & 126.02 & 1.22 \\
\hline & Glycine $\mathrm{HCl}$ buffer & $0.0067(0.9823)$ & $0.0064(0.9768)$ & 103.45 & 108.30 & 0.99 \\
\hline
\end{tabular}

${ }^{\mathrm{a}} \mathrm{k}=$ reaction rate constant; ${ }^{\mathrm{b}} \mathrm{t}_{1 / 2}=$ half-life of anthocyanins degradation; ${ }^{\mathrm{C}} \mathrm{E}_{\mathrm{a}}=$ Activation Energy; ${ }^{\mathrm{d}}$ Numbers in parentheses are the determination coefficients.

hanced but barberry anthocyanins appeared more stable in this situation.

Eggplant peels anthocyanins in comparison to these of other materials showed lesser stability during storage especially at $-20^{\circ} \mathrm{C}$, which was reflected in the $\mathrm{k}$ values (Table 5).

The first order reaction rate constant $(\mathrm{k})$, the half-life of anthocyanins $\left(\mathrm{t}_{122}\right)$ and other kinetic parameters of samples are shown in Table 5. The required time for $50 \%$ degradation of red cabbages anthocyanins at $-20^{\circ} \mathrm{C}$ is always longer than at $7^{\circ} \mathrm{C}$, which is contrary to other types of anthocyanin samples. These results showed that changes of anthocyanin content were greater at the lower temperature of storage. At both temperatures, the final contents were lower than the initials. Similar results were described by Concellon et al. [2007] who worked with Solanum melongena variety of eggplant. Here, the decrease of anthocyanin content during the freezing could be carried by the antioxidant activity of anthocyanin. Anthocyanin is one of the flavonoid compounds with a stronger reducing power, and possibly plays some important role as an antioxidant. Wang \& Xu [2007] have also found that a high content of anthocyanin during low temperature storage $\left(5^{\circ} \mathrm{C}\right)$ was less affected by temperature.

\section{Temperature dependence}

The dependence of the degradation of anthocyanins on temperature was determined by calculating the activation energy (Ea) for two temperature area.

Eggplant peel solution resulted in higher Ea values during storage at both $7{ }^{\circ} \mathrm{C}$ and $-20^{\circ} \mathrm{C}$ storage (Table 5). As compared to the solution, lower Ea values were obtained by barberry anthocyanin during storage at cold temperature. Since high activation energy reactions are more sensitive to temperature changes, anthocyanins of eggplant peel are more susceptible to temperature elevation during storage.

There were differences among the Ea values for the thermal degradation of individual anthocyanins of samples at different solutions. In most cases, the Ea of citrate buffers were the highest, which indicated that anthocyanins are more stable at this condition. But the calculated Ea values of anthocyanins of barberry ranged from 8.6 to $0.99 \mathrm{~kJ}$ $\mathrm{mol}^{-1}$ in water and citrate buffer solutions, respectively. It means that the aqueous solution of barberry anthocyanin is more stable.

\section{CONCLUSIONS}

In this study, it was found that the citric acid solution was one of the best solvents for phenolic and anthocyanin extraction that showed the best scavenging activity of DPPH radical. Considering that citric acid is a weak organic acid which is a natural preservative and also used to add an acidic or sour taste to foods and drinks (E330), it has a great potential for food ingredients extraction. However, further studies on the ability of citric acid for the extraction of anthocyanin form different sources are needed.

The present study provides detailed information regarding changes in the kinetic stability of anthocyanins in red cabbage, eggplant peel and barberry at temperatures of $7^{\circ} \mathrm{C}$ and $-20^{\circ} \mathrm{C}$ in different solutions. The present data shows that degradation of anthocyanins follows first-order reaction kinetics. The stability of anthocyanins depends on temperature and $\mathrm{pH}$. During frozen storage and in the absence of acids anthocyanins degraded more quickly. Thus more stable natural food colorant based on anthocyanins could be achieved by using barberry and red cabbage acidified solutions. Although the acidified solution is not necessary for barberry anthocyanins.

\section{RESEARCH FUNDING}

The study was funded by Department of Food Science and Technology, Tehran Science and Research Branch of Islamic Azad University. 


\section{ACKNOWLEDGEMENTS}

The authors gratefully acknowledge Professor Maryam Mizani and Professor Mehrdad Azin for their valuable comments and helpful suggestions.

\section{REFERENCES}

1. Akbulut M., Calisir S., Marakoglu T., Coklar H., Some physicomechanical and nutritional properties of Berberis vulgaris $L$. fruits. J. Food Process. Eng., 2009, 32, 479-511.

2. Astadi I.R., Astuti M., Santoso U., Nugraheni P.S., In vitro antioxidant activity of anthocyanins of black soybean seed coat in human low density lipoprotein (LDL). Food Chem., 2009, 112, 659-663.

3. Berenji Ardestani S., Sahari Ali M., Barzegar M., Abbasi S., Some physicochemical properties of Iranian native barberry fruits (abi and poloei): Berberis integerrima and Berberis vulgaris. J. Food Pharm. Sci., 2013, 1, 60-67.

4. Boulekbache-Makhlouf L., Medouni L., Medouni-Adrar S., Arkoub L., Madani K., Effect of solvents extraction on phenolic content and antioxidant activity of the byproduct of eggplant. Ind. Crop. Prod., 2013, 49, 668- 674.

5. Boulton R., The copigmentation of anthocyanins and its role in the color of red wine: a critical review. Am. J. Enol. Vitic., 2001, $52,67-87$.

6. Cao S.Q., Liu L., Pan S.Y., Thermal degradation kinetics of anthocyanins and visual color of blood orange juice. Agric. Sci. China, 2011, 10, 1992-1997.

7. Castaneda-Ovando A., Pacheco-Hernandez L., Paez-Hernandez E., Rodriguez J.A., Galan-Vidal C.A., Chemical studies of anthocyanins: a review. Food Chem., 2009, 113, 859-871.

8. Chandrasekhar J., Madhusudhan M.C., Raghavarao K.S.M.S., Extraction of anthocyanins from red cabbage and purification using adsorption. Food Bioprod. Process., 2012, 90, 615-623.

9. Charron C.S., Kurilich A.C., Clevidence B.A., Simon P.W., Harrison D.J., Britz S.J., Bioavailability of anthocyanins from purple carrot juice: effects of acylation and plant matrix. J. Agric. Food Chem., 2009, 57, 1226-1230.

10. Chen Z., Bertin R., Froldi G., EC50 estimation of antioxidant activity in DPPH assay using several statistical programs. Food Chem., 2013, 138, 414-420.

11. Concellón A., Anon M., Chaves A.R., Effect of low temperature storage on physical and physiological characteristics of eggplant fruit (Solanum melongena L.). LWT - Food Sci. Technol., 2007, 40, 389-396.

12. Eun-Ju J., Myung-Suk B., Eun-Kyung J., Young-Hong J., Seung-Cheol L., Antioxidant activity of different parts of eggplant. J. Med. Plants Res., 2011, 18, 5, 4610-4615.

13. Fleschhut J., Kratzer F., Rechkemmer G., Kulling S.E., Stability and biotransformation of various dietary anthocyanins in vitro. Eur. J. Nut., 2006, 45(1), 7-18.

14. Forbes-Hernandez T.Y., Giampieri F., Gasparrini M., Mazzoni L., Quiles J.L., Alvarez-Suarez J.M., Battino M., The effects of bioactive compounds from plant foods on mitochondrial function: A focus on apoptotic mechanisms. Food Chem. Toxicol., 2014, 68, 154-182.

15. Gallo M., Naviglio, D., Ferrara L., Nasunin, an antioxidant anthocyanin from eggplant peels, as natural dye to avoid food allergies and intolerances. Eur. Sci. J., 2014, 10, 9, 158-167.
16. Garna H., Mabon N., Wathelet B., Paquot M., New method for a two-step hydrolysis and chromatographic analysis of pectin neutral sugar chains. J. Agri. Food Chem., 2004, 52, 4652-4659.

17. Giampieri F., Alvarez-Suarez J.M., Battino M., Strawberry and Human Health: Effects beyond antioxidant activity. J. Agric. Food Chem., 2014a, 62, 3867-3876.

18. Giampieri F., Alvarez-Suarez J.M., Mazzoni L., Forbes-Hernandez T.Y., Gasparrini M., Gonzàlez-Paramàs A.M., Santos-Buelga C., Quiles J.L., Bompadre S., Mezzetti B., Battino M., Polyphenol-rich strawberry extract protects human dermal fibroblasts against hydrogen peroxide oxidative damage and improves mitochondrial functionality. Molecules, 2014b,19, 7798-816.

19. Giusti M.M., Wrolstad R., Acylated anthocyanins from edible sources and their applications in food systems. Biochem. Eng. J., 2003, 14, 217-225.

20. Holzwarth M., Korhummel S., Carle R., Kammerer D.R., Impact of enzymatic mash maceration and storage on anthocyanin and color retention of pasteurized strawberry purées. Eur. Food Res. Tech., 2012, 234, 207-222.

21. Howard L.R., Brownmiller C., Prior R.L., Improved color and anthocyanin retention in strawberry puree by oxygen exclusion. J. Berry Res., 2014, 4(2), 107-116.

22. Igarashi K., Yoshida T., Suzuki E., Antioxidative activity of nasunin in Chouja-nasu (Little eggplant, Solanum melongena L. 'Chouja'). Nippon Kogyo Gakkaishi., 1993, 40, 138-143.

23. Jing P., Zhao S.J., Ruan S.Y., Xie Z.H., Dong Y., Yu L., Anthocyanin and glucosinolate occurrences in the roots of Chinese red radish (Raphanus sativus L.), and their stability to heat and pH. Food Chem., 2012, 133, 1569-1576.

24. Kamiloglu S., Boyacioglu D., Capanoglu E., The effect of food processing on bioavailability of tomato antioxidants. J. Berry Res., 2013, 3(2), 65-77.

25. Kapasakalidis P.G., Rastall R.A., Gordon M.H., Extraction of polyphenols from processed black currant (Ribes nigrum L.) residues. J. Agric. Food Chem., 2006, 54, 4016-4021.

26. Kara S., Ercelebi E.A., Thermal degradation kinetics of anthocyanins and visual colour of Urmu mulberry (Morus nigra L.). J. Food Eng., 2013, 116, 541-547.

27. Kirca A., Cemeroglu B., Degradation kinetics of anthocyanins in blood orange juice and concentrate. Food Chem., 2003, 81, 583-587.

28. Koncic M.Z., Kremer D., Karlovic K., Kosalec I., Evaluation of antioxidant activities and phenolic content of Berberis vulgaris L. and Berberis croatica Horvat. Food Chem. Toxicol., 2010, 48, 2176-2180.

29. Konczak I., Zhang W., Anthocyanins-more than nature's colours. J. Biomed. Biotechnol., 2004, 5, 239-240.

30. Li J., Li X.D., Zhang Y., Zheng Z.D., Qu Z., Liu M., Zhu S., Liu S., Wang M., Qu L., Identification and thermal stability of purple-fleshed sweet potato anthocyanins in aqueous solutions with various $\mathrm{pH}$ values and fruit juices. Food Chem., 2013, 136, 1429-1434.

31. McDougall G.J., Fyffe S., Dobson P., Stewart D., Anthocyanins from red cabbage-Stability to simulated gastrointestinal digestion. Phytochemistry, 2007, 68, 1285-1294.

32. Medina M.B., Determination of the total phenolics in juices and superfruits by a novel chemical method. J. Funct. Food, 2011, 3, 79-87. 
33. Mosier N.S., Ladisch C.M., M.R., Ladisch A., Characterization of acid catalytic domains for cellulose hydrolysis and glucose degradation. Biotechnol. Bioeng., 2002, 79(6), 610-618.

34. Nisha P., Nazar P.A., Jayamurthy P., A comparative study on antioxidant activities of different varieties of Solanum melongena. Food Chem. Toxicol., 2009, 47, 2640-2644.

35. Rein M., Copigmentation reactions and color stability of berry anthocyanins. Academic Dissertation, Helsinki: University of Helsinki, 2005, pp. 10-14, [https://helda.helsinki.fi/bitsream/ handle/10138/20822/copigmen.pdf].

36. Shao-Qian C., Liang L., Si-yi P., Thermal degradation kinetics of anthocyanins and visual color of blood orange juice. Agric. Sci. China, 2011, 10(12), 1992-1997.

37. Sharifi A., Hassani B., Extraction methods and stability of color extracted from barberry pigments. Int J Agr Sci., 2012, 2(4), 320-327.

38. Silva-Pereira M.C., Teixeira J.A., Pereira-Júniora V.A., Stefani R., Chitosan/corn starch blend films with extract from Brassica oleraceae (red cabbage) as a visual indicator of fish deterioration. LWT - Food Sci. Technol., 2015, 61, 258-262.

39. Singh J., Upadhyay A.K., Bahadur A., Singh B., Singh K.P., Rai M., Antioxidant phytochemicals in cabbage (Brassica oleracea L. var. capitata). Sci. Hort., 2006, 108, 233-237.

40. Todaro A., Cimino F., Rapisarda P., Catalano A.E., Barbagallo R.N., Spagna G., Recovery of anthocyanins from eggplant peel. Food Chem., 2009, 114, 434-439.

41. Wang W.D., Xu S.Y., Degradation kinetics of anthocyanins in blackberry juice and concentrate. J. Food Eng., 2007, 82, 271-275.

Submitted: 4 December 2014. Revised: 8 June, 9 June and 15 November 2015. Accepted: 7 December 2015. Published on-line: 12 July 2016. 
